Trakya Eğitim Dergisi

Cilt 10, Sayı 1

Ocak 2020, 64-75

Geliş Tarihi: 20.02 .2019

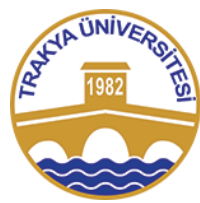

ISSN: 2630-6301

Doi: $10.24315 /$ tred.529721

Araștırma Makalesi

Research Article
Trakya Journal of Education

Volume 10, Issue 1

January 2020, 64-75

\title{
EBA İçerikleriyle Harmanlanmış Öğretim Uygulamasının Öğrencilerin Fen Bilimleri Dersindeki Akademik Başarılarına ve Tutumlarına Etkisi
}

\section{The Effects of Learning Blended with EBA Content on Students' Academic Achievement and Attitudes Toward Science Course}

\author{
Merve KADIRHAN ${ }^{1}$, Özgen KORKMAZ ${ }^{2}$
}

\begin{abstract}
ÖZ: Bu araştırmanın amacı, EBA kullanılarak harmanlanan Fen Bilimleri eğitiminin öğrencilerin akademik başarılarına ve tutumlarına etkisini belirlemektir. Araştırmada ön test-son test kontrol gruplu yarı deneysel desen kullanılmıştır. Araştırmanın çalışma grubu bir ortaokulun 6. Sınıfinda öğrenim gören 75 öğrenciden oluşmaktadır. Araştırma verileri araştırmacılar tarafindan geliştirilen Fen Bilimleri Dersi Başarı Testi (KR-20= $0,80)$ ve Şener ve Taş tarafindan geliştirilen Fen Bilimleri Dersine Yönelik Tutum Ölçeği (Cronbach Alpha $=0.87$ 'dir) kullanılarak toplanmıştır. Deney grubunda EBA içerikleri kullanılarak tasarlanan harmanlanmış öğrenme uygulaması gerçekleştirilirken, kontrol grubunda geleneksel öğretim uygulaması gerçekleştirilmiştir. Toplanan veriler için aritmetik ortalama ve standart sapma hesaplanmış ve veriler $t$ testi ile analiz edilmiştir. Araştırmada deneysel uygulama öncesinde hem deney hem de kontrol grubundaki öğrencilerin fen bilgisi dersine yönelik tutumlarının oldukça yüksek olduğu ve EBA içerikleriyle harmanlanmış Fen Bilimleri Dersi ögrencilerin fen bilgisi dersine yönelik akademik başarılarına ve tutumlarına katkı sağladığı şu sonuçlarına ulaşılmıştır.
\end{abstract}

Anahtar sözcükler: EBA, harmanlanmış öğrenme, fen eğitimi

\begin{abstract}
The aim of this study is to determine the impact of science education blended with EBA content on students' academic achievements and attitudes. In the study, a quasi-experimental research design with pretest- posttest control group was used. The study group consists of 75 students who study in the sixth grade of a secondary school. The research data were collected using the achievement test developed by the researchers, and the attitude scale for the science course (Cronbach Alpha $=0.87$ ) designed by Şener ve Taş. In the experimental group, the blended learning application was designed using EBA content and the traditional teaching application was implemented in the control group. The data collected were analyzed using arithmetic mean, standard deviation and $t$ test. As a result; prior to experimental implementation, the students in both groups have high attitudes toward science course. Blended science course contributes to students' academic achievement and attitudes toward science course.
\end{abstract}

Keywords: EBA, blended learning, science education

Cite this article as:

Kadirhan, M. \& Korkmaz, Ö. (2020). The effects of learning blended with eba content on students' academic achievement and attitudes toward science course. Trakya Eğitim Dergisi, 10(1), 64-75.

\section{EXTENDED ABSTRACT}

\section{Introduction}

Students are exposed to a special science course when they arrive in secondary school, while they are referring to the subjects of science in primary school from a general point of view. Students perceive science as a difficult course (Teker, Kurt \& Karamustafaoğlu, 2017). However, the science course can be considered as an easy course for visual elements, interactive video samples, analogous activities. With the advancement of technology, new approaches can be considered to be introduced into the learning process. In addition to the many advantages of developing technology and e-learning into learning environments, it has brought with it many disadvantages (Balaman \& Tüysüz, 2011). In this context, blended learning is on the agenda. Blended learning is an approach that involves both distance education and traditional education (Usta \& Mahiroğlu, 2008). In this context, the aim of the research is to determine the impact of blended science education on students ' academic achievements and attitudes.

\footnotetext{
${ }^{1}$ Yüksek Lisans Öğrencisi, Amasya Üniversitesi, mervekadirhan@gmail.com, orcid.org/0000-0002-9170-389X

${ }_{2}^{2}$ Prof. Dr., Amasya Üniversitesi, Tel: 03582600066-1515, ozgenkorkmaz@ gmail.com, orcid.org/0000-0003-4359-5692
} 


\section{Method}

In the study, a quasi-experimental research design with pretest-posttest control group was used. The study group consisted of 75 6th grades students who are at Osmangazi Secondary School in Gebze District, Kocaeli province. The research data were collected using the achievement test $(\mathrm{Kr}-20=0.80)$ developed by the researchers and the attitude scale (Cronbach Alpha $=0.87$ ) for the science course. Both experimental and control groups were trained within the scope of Systems Unit in Our Body. For the gains of this unit, a total of four weeks is reserved for four hours per week. 2 weeks of this period is divided into circulatory system, 1 Week is divided into respiratory system, 1 Week is divided into excretory system. In both groups, the duration of the subjects is equal, and the same gains are made. In the experimental group, the blended learning application was designed using EBA content and the traditional teaching application was realized in the control group.

\section{Results}

Prior to experimental application, students in both experimental and control groups have a high level of attitudes towards science course. It is possible to say that the science course is interesting because it contains the solution of many problems, students face in their daily lives. It is expected that they will take a positive attitude towards the lesson because they find a part of the lesson at every moment of life. The preliminary score results also confirm this. The science course can provide students with more concrete information compared to other courses. Therefore, students ' attitudes towards the course are also high. Blended with Eba content, science course contributes significantly more to students' academic achievement in science course than in traditional method. When the literature is analyzed, the academic achievement level was significantly higher in all of the previous studies, regardless of which course is blended. Blended with Eba content, the science course contributes significantly more to students' attitudes toward everyday life and the new learning factor. On the other hand, the mean of the experimental group is higher attitude than the control group, although it is not significant in terms of other factors.

\section{Conclusion}

In a study carried out by Uyanık (2017), it was determined that the attitudes of fourth grade students towards the science course were slightly above the intermediate level. Similarly, it was found that students have a positive attitude towards science course. In the research, it was determined that there was a significant correlation between the achievement of the students in having positive attitudes towards science course or other courses related to science (Türkmen, 2002; Kozcu-Çakır, Şenler \& Göçmen-Taşkın, 2007). In this context, it is very pleasing that the students' attitudes towards the science course are high.

A meta-analysis study of 36 experimental results from 225 studies completed between 2000 and 2016 by Çırak, Kurt, Yıldırım and Cücük (2018) reported that the blended learning is contribute strongly on achievement of students and blended learning has a $70.8 \%$ added value on achievements. On the other hand, it was determined that blended learning has more positive results in achievement of students compared to face-to-face learning and online learning. In addition, it has been determined that blended learning enriched with different methods has a more positive effect on achievement of students than conventional blended learning.

When the literature is examined, there are many evidences that science education with blended learning and have contributed positively to students' attitudes (Akkuş \& Keskin, 2016; Çakır, Şenler \& Taşkın, 2007; Çiftli \& Dönmez, 2015; Güler \& şahin, 2015). On the other hand, studies on the attitudes of blended learning have examined significant differences among students not only on certain levels but also on age variables (Güler \& şahin, 2015). In this context, it is recommended that teachers use a blended learning approach in their lessons. 


\section{GİRIȘ}

Öğrenciler fen bilimleri dersiyle ilkokulun ilk yıllarında tanışmaktadırlar. Ancak erken yaşlarda tanıştıkları bir ders olmasına rağmen öğrencilerin fen bilimleri dersini zor bir ders olarak algıladıkları belirtilmektedir (Teker, Kurt \& Karamustafaoğlu, 2017). Oysa fen bilimleri dersi görsel öğelere, etkileşimli video örneklerine, benzeşim kurulan etkinliklere yer verildiğinde algılanması kolay ve öğrenme başarısı yüksek olabilecek dersler arasında sayılabilir. Gelişen teknoloji ile birlikte öğrenme ortamlarını zenginleștirmeye dönük pek çok yeni firsat doğmuștur. Bu firsatlardan birisinin de eöğrenme ortamları olduğu söylenebilir. E-öğrenme ortamlarının birtakım dezavantajları da olmakla birlikte (Balaman \& Tüysüz, 2011) özellikle yüz yüze öğrenme ortamlarına entegre edilerek kullanılması durumunda önemli katkılar sağlayabileceği vurgulanmaktadır. Böylece e-öğrenme ortamları ile yüz yüze öğrenme ortamlarının avantajları bir araya getirilerek daha etkili öğrenme ortamları tasarlanabilir. E-öğrenme ve yüz yüze öğrenme ortamları birlikte kullanılarak tasarlanan öğretim alan yazında harmanlanmış öğrenme olarak isimlendirilmektedir (Çırak, 2017). Thorne (2007, 16) harmanlanmış öğrenmenin, e- öğrenme ile gelen teknolojik gelişmelerin sunduğu fırsatların, yüz yüze öğrenme ortamlarıyla bütünleştirilmesi için bir firsat olduğunu vurgulamaktadır.

Geleneksel öğrenme yaklaşımında ev ödevi verilmediği takdirde öğrencilerin evde derse devam etme ihtimalleri azalabilir. Öğrencilerin evde konuyu öğretmenlerinin sunuş şekliyle bir kez daha tekrar etme olanakları olmamaktadır. Oysaki harmanlanmış bir öğrenme yaklaşımı ile öğrencilerin sınıf ortamında öğrendikleri konuyu evde Eğitim Bilişim Ağı (EBA)'nda bulunan ders içerikleriyle tekrar etme firsatları bulunmaktadır. Hatta öğrencilerin derse gelmeden önce hazırlanma ve ders bitiminde öğretmenlerinin EBA'ya yüklemiş olduğu ders materyallerini defalarca izleme ve okuma firastları bulunmaktadır. Yapılan bu işlemler çerçevesinde de eğitim-öğretimin kalitesi artmakta ve harmanlanmış öğrenmenin öğrenciler üzerinde kalıcı etkisi görülmektedir (Akkuş \& Keskin, 2016; Morgan, 2002; Smelser, 2002).

Wilson ve Smilanich $(2015,12)$ harmanlanmış öğrenmeyi en geniş şekliyle öğrenme hedeflerine ulaşmak için, en etkili öğretim çözümlerini birlikte eşgüdümlü şekilde kullanmak olarak tanımlamaktadırlar. Singh ve Reed (2001) ise harmanlanmış öğrenmeyi mükemmelleştirmek amacıyla birden fazla öğrenme ortamının kullanıldığ Harmanlanmış eğitim hem uzaktan eğitimi hem de geleneksel eğitimi içine alan bir yaklaşımdır (Usta \& Mahiroğlu, 2008). Bu sebeple sınıf içerisinde öğretmen geleneksel yöntemlerle (sunuş yolu, model gösterimi, basit deneyler vb.) öğretim yapmasının yanında, araştırmanın amacı olan EBA içeriklerini de kullanarak (ders içerikleri, etkileșimli örnekler, online sınavlar, video, sanal deneyler vb.) öğretimi harmanlamış olmaktadır. Bu sayede öğrenciler daha keyifli ve kalıcı bir öğrenme sağlayabilmektedir. Horton, (2000) harmanlanmış öğrenmenin birçok farklı şekilde yapıldığını vurgulamaktadır. Graham, $(2006,13)$ sadece yüz yüze veya e-öğrenme ile yürütülen bir dersin harmanlanmış öğrenme ortamından beklenen faydalar doğrultusunda yenilenmesi söz konusu olduğunda; mümkün kılan harmanlama, zenginleştiren harmanlama ve dönüştüren harmanlama olmak üzere üç ayrı harmanlama türü olduğunu ifade etmektedir. Bu araştırma kapsamında tasarlanan harmanlama türü zenginleştiren harmanlamaya örnektir. Harmanlanmış öğrenme ortamları ve öğrenme yöntemleri de farklılaşmakta, hatta öğrenme yöntemlerinin kullanılış şekli, uygulama metodu da değişebilmektedir (Yolcu, 2015). Bir başka ifadeyle yüz yüze ve e-öğrenme yaklaşımlarına ilişkin stratejiler farklı yoğunluklarda ve farklı kombinasyonlarda kullanılabilmektedir. Bu sebeple harmanlanmış öğrenme ortamlarında uygulanan tek bir yöntem bulunmamaktadır (Dağ, 2011). Öğrencilere sınıf ortamının dışında da iş birliği içerisinde çalışma firsatı sunulabilmektedir. Bu yönüyle harmanlanmış öğrenme öğrencilerin kişisel becerilerini geliştirebileceği ortamlar sağlamaktadır (Yolcu, 2015).

Son yıllarda teknoloji hızla ilerlemiş olmasına rağmen, eğitim-öğretimin merkezi olan okulların tam olarak teknolojik donanıma sahip olmadıkları söylenebilir. Bu çerçevede örneğin fen bilimleri dersinin daha anlamlı ve etkin kılınması için laboratuvar, 3 boyutlu ders materyalleri, mikroskop gibi birçok materyale ihtiyaç duyulmaktadır. Ancak buna karşın Fatih projesi kapsamında pek çok sınıfa akıllı tahta ve internet firsatının da sunulduğu da söylenebilir. Aynı zamanda artık hemen hemen her evde imkanlar dahilinde internet ve bilgisayar ya da tablet bulunmaktadır. Elde bulunan bu firsatlarla harmanlanmış öğrenme etkili bir şekilde öğrencilere sunulabilir. Gerçek deneyleri yapma firsatı olmaması durumunda, öğrenciler sanal ortamlarda bulunan uygulamalar, etkileşimli örnekler sayesinde sanal deneylerin sonuçlarına ulaşabilmektedir. $\mathrm{Bu}$ da harmanlanmış öğrenmenin en önemli 
avantajlarından biridir (Akkuş \& Keskin, 2016). Harmanlanmış öğrenme yaklaşımında sınıf içerisinde yüz yüze etkileşim, video destekli paylaşım, internet tabanlı ev ödevi sunulabilmektedir. Böylece çoklu ortam olanakları sınıf taşınarak başarının desteklenmesi mümkün olabilir. Harmanlanmış öğrenme yaklaşımı çok çeşitli şekillerde kullanılabilmektedir. Bu çalışmada Milli Eğitim Bakanlığı'nın Fatih projesi kapsamında geliştirmiş olduğu EBA portalı kullanılmıştır.

EBA, (2019)'a göre bu ortam; gereksinim duyulduğu her zaman ve her yerde kullanabilen bir ortamdır. Bu nedenle EBA'nın, öğrenmenin yalnızca okulda değil, okul dıșında da gerçekleștirilmesine yardımcı olduğu vurgulanmaktadır. Bu çerçevede EBA'nın amacının bilgi teknolojileri aracılığıyla etkili materyal kullanımını destekleyip teknolojinin eğitime entegrasyonunu sağlamak olduğu vurgulanmaktadır. Öte yandan EBA' da yer alan içeriklerin sınıf düzeyleri gözetilerek ve ön kontrolden geçirilmiş e-içerikler sunduğu ifade edilmektedir. Bu nedenle araştırmada EBA eğitim portalının kullanılması uygun görülmüştür. Fen bilimleri dersi müfredatının 2017 yılında değişmesiyle 2018-2019 eğitim öğretim yılında 6. sınıflara vücudumuzda sistemler ünitesi kazanımları dahil edilmiştir. Ünite içeriğinin soyut ve çok fazla sözel bilgi içermesinden dolayı öğrenilmesi zorlaşabilmektedir. Öğrenme zor olduğunda buna bağlı olarak akademik başarı da düşmektedir. Öte yandan literatüre bakıldığında fen bilgisi dersinde harmanlanmış öğrenmenin etkisine dönük sınırlı sayıda çalışma bulunmaktadır. $\mathrm{Bu}$ nedenle bu araştırmanın amacı da Fen bilimleri dersinde EBA içerikleriyle harmanlanmış bir öğretim uygulamasının, öğrencilerin akademik başarılarına ve öğrencilerin fen bilimleri dersine tutumları üzerinde etkisini belirlemek şeklinde belirlenmiştir.

\subsection{Araştırmanın Problemi}

Fen bilimleri dersinde EBA içerikleriyle harmanlanmış bir öğretim uygulamasının öğrencilerin akademik başarıları ve fen bilimleri dersine yönelik tutumları üzerinde etkisi var mıdır?

\subsection{Alt Problemler}

- Deneysel uygulama öncesinde grupların fen bilimlerine yönelik akademik başarıları ve tutumları benzer midir?

- EBA içerikleriyle harmanlanmış fen bilimleri dersinin 6. Sınıf öğrencilerinin sistemler ünitesindeki akademik başarılarına geleneksel öğretime göre anlamlı bir katkısı var mıdır?

- EBA içerikleriyle harmanlanmış fen bilimleri dersinin 6. Sınıf öğrencilerinin fen bilimleri dersine dönük tutumları üzerinde geleneksel öğretime göre anlamlı bir katkısı var mıdır?

\section{YÖNTEM}

\subsection{Araştırmanın Deseni}

Araştırmada ön test-son test kontrol gruplu yarı deneysel desen kullanılmıştır. Bu model, birden çok grup içerisinden yansız olarak bir deney bir de kontrol grubunun eşleştirilerek oluşturulması esasına dayanmaktadır (Büyüköztürk, 2002: 206). Çalışma kapsamında iki grup belirlenerek ön test uygulaması yapıldıktan sonra 4 hafta süre ile deney grubunda EBA içerikleriyle harmanlanmış öğretim uygulaması yapılmış ve kontrol grubunda ise geleneksel öğretim uygulanmıştır. 4 hafta sonunda son test uygulaması yapılarak her iki grubun sonuçları karşılaştırılmıştır.

\section{2. Çalışma Grubu}

Araştırmada uygun örnekleme yöntemi tercih edilmiştir. Bu yöntemde araştırmacı, yakın ve erişilmesi kolay olan bir durumu seçer ve çoğu zaman araştırmacının diğer örnekleme yöntemini kullanma firsatının olanağının olmadığı durumlarda kullanılır (Kılıç, 2013). Bu araştırmada da araştırmacılardan birisinin öğretmen olarak görev yaptığı Kocaeli ili Gebze ilçesi Osmangazi Ortaokulunda 6. sinıflardan 75 öğrenci çalışma grubunu oluşturmuştur. 6/A ve 6/E şubeleri arasında herhangi bir seçim yapılmaksızın rastgele kontrol ve deney grubu belirlenmiştir. 6/A şubesinde bulunan 40 öğrenci (22 kız, 18 erkek) kontrol grubu, 6/E şubesinde bulunan 35 öğrenci (18 kız, 17 erkek) deney grubu olarak belirlenmiştir. 


\subsection{Veri Toplama Araçları}

Araştırma verileri fen bilimleri dersi başarı testi ve fen bilimleri dersine yönelik tutum ölçeği kullanılarak toplanmıştır. Ölçeklerle ilgili detaylar şöyledir:

Fen Bilimleri Dersi Başarı Testi: Fen Bilimleri Dersi Başarı Testi araştırmacılar tarafindan, öğrencilerin fen bilimleri dersine dönük akademik başarılarını ölçmek amacıyla İnternet kaynakları (Morpa kampüs, EBA, Fenokulu), Z-kitaplar (Çanta Yayınları, Ata Yayıncılık, Arı Yayınları) kullanılarak hazırlanmıştır. Fen Bilimleri Başarı Testi deneysel süreci kapsayan kazanımları tek tek ölçebilen 25 çoktan seçmeli sorudan oluşmuştur. Elde edilen test, 7. Sınıf öğrencilerinden oluşan 120 öğrenciye uygulanarak, pilot uygulama yapılmıştır. Pilot çalışma sonunda ayırt edicilik düzeyi 0.3 'ün altındaki 5 madde testten çıkarılmıştır. Çıkarılan maddelerin ölçmeyi amaçladığı kazanımların, testte yer alan başka maddeler tarafında ölçüldügü gözlendiğinden, kapsam geçerliliğini olumsuz etkilemediği sonucuna varılmıştır. Pilot çalıma sonucunda testin madde güçlük indeksi 0.56 ' dır. Terstin iç tutarlılık katsayısı ise KR-20 $=0.80$ olarak belirlenmiştir. Ölçekte kalan maddelerin ayırt edicilik katsayıları ise Tablo 1'de özetlenmiştir.

Tablo 1. Maddelerin Ayırt Edicilik Düzeyleri

\begin{tabular}{cccc}
\hline Maddeler & Ayrrt Edicilik & Maddeler & Ayırt Edicilik \\
\hline 1. & 0.66 & 11 & 0.77 \\
2. & 0.59 & 12 & 0.33 \\
3. & 0.40 & 13 & 0.48 \\
4. & 0.48 & 14 & 0.37 \\
5. & 0.51 & 15 & 0.81 \\
6. & 0.33 & 16 & 0.40 \\
7. & 0.51 & 17 & 0.85 \\
8. & 0.62 & 18 & 0.51 \\
9. & 0.40 & 19 & 0.66 \\
10. & 0.48 & 20 & 0.51 \\
\hline
\end{tabular}

Bu sonuçlar doğrultusunda Fen Bilimleri Dersi Akademik Başarı Testinin geçerli ve güvenilir ölçümler yapabileceği söylenebilir.

Fen Bilimleri Dersine Yönelik Tutum Ölçeği: Araştırma kapsamında öğrencilerin derse dönük tutumlarını belirlemek amacıyla Şener ve Taş (2016) tarafından geliştirilmiş ve geçerlilik-güvenilirlik çalışması yapılmış olan Fen Bilimleri Dersine Dönük Tutum ölçeği kullanılacaktır. Ölçek 5 faktör altında toplanabilen 10 olumlu ve 11 olumsuz madde olmak üzere toplam 21 maddeden oluşmaktadır. 5'li likert tipindeki ölçeğin açıklanan varyans oranı \%53.56, Cronbach Alpha güvenirlik katsayısı 0.87 'dir. Faktörlere ilişkin iç tutarlılık katsayıları sırasıyla; Günlük yaşam ve yeni bilgiler öğrenme faktörü için 0.82, Uygulamada güçlük faktörü için 0.61, Problem çözme faktörü için 0.74, Motivasyon faktörü için 0.67, Endişe faktörü için ise 0.52'dir.

\subsection{Deneysel işlemler}

Deneysel çalışma kapsamında hem deney hem de kontrol gruplarına Vücudumuzda Sistemler Ünitesi kapsamında öğretim yapılmıştır. Bu ünitenin kazanımları için haftada dört saat olmak üzere toplam dört hafta ayrılmıştır. Bu sürenin 2 haftası dolaşım sistemine, 1 haftası solunum sistemine, 1 haftası da boşaltım sistemine ayrılmıştır. Her iki grupta da konuların süresi eşittir ve aynı kazanımlar işlenmiştir. Deneysel süreçte kazandırılmaya çalışılan kazanımlar şöyledir:

- Dolaşım sisteminde; dolaşım sistemi yapı ve organlarını görevleriyle birlikte açıklar. Kanın yapısını bilir ve kan bağışının önemine değinir.

- Solunum sisteminde; solunum sistemi yapı ve organlarını görevleriyle birlikte açıklar.

- Boşaltım sisteminde; boşaltım sistemi yapı ve organlarını görevleriyle birlikte açıklar.

Deneysel uygulama öncesinde deney ve kontrol grubuna öntest uygulanmış, deneysel süreç tamamlandıktan sonra ise aynı testler sontest olarak tekrar uygulanmıştır. Hem deney hem de kontrol grubunda öğretim uygulaması aynı öğretmen tarafindan yürütülmüştür. 
Deney Grubu: Deney grubundaki öğrencilere EBA'dan 6/E adlı bir grup kurulmuş ve öğrencilerle ders dış1 iletişim sağlanmıştır. Kurulan grup üzerinden öğrencilerle vücudumuzda sistemler konusu ile ilgili çalışma yaprağı paylaşılmış ve ders bitiminde sistemler ünitesinde bulunan her bir sistemle ilgili evde çalışmaları söylenmiş̧ir. Her sistemin öğretmen tarafından konu anlatımı bitiminde EBA'da paylaşılan video içerikleriyle konu anlamlı hale getirilerek, kalıcı öğrenme sağlanmaya çalışılmıştır. Her sistem bittiğinde EBA'da oluşturulan grup üzerinden konu sonu testi ile dönüt verilerek tam öğrenme uygulanmaya çalışı1mıştır.

$\mathrm{Bu}$ çalışma kapsamında Zenginleştiren harmanlama yapılmıştır. $\mathrm{Bu}$ harmanlama türünde öğrenme ortamında köklü değişiklikler yapılmadan, öğrenme ortamına yeni eklemeler yer alır. Geleneksel yüz yüze öğretime Web tabanlı uygulamalarla eklenen farklı kaynaklar, destekleyici materyaller bu tür bir harmanlamaya örnektir (Graham, 2006, 13). Bu kapsamda yüz yüze öğrenme ortamına EBA e-öğrenme ortamı eklenerek bir harmanlama yapılmıştır. EBA modülü üzerinde öğrencilere grup kurularak içerikler paylaşılmıştır. Bu gruplarda öğrenciler yüz yüze dersten önce çevrimiçi ortamda konuya ilişkin ön bilgileri edinmiş, yüz yüze derslerde ise bu konulara ilişkin alıştırma yapılarak, konular pekiştirilmeye çalışılmıştır. Bu sayede öğrenciler EBA'da yer alan videoları izleyerek derse geldikleri için yüz yüze oturumlarda konunun pekiştirilmesi için daha fazla etkinlik yapma firsatı bulunmuştur.

EBA portalı dersin her bir ünitesi ile ilgili ayrı ayrı kazanımlara yönelik 2-3 dakikalık videolar bulundurmaktadır. Yapılan araştırmada dersler Şekil 1'deki gibi EBA içerikleri kullanılarak harmanlanmıştır. Etkinliklerden birkaç örnek şöyledir;

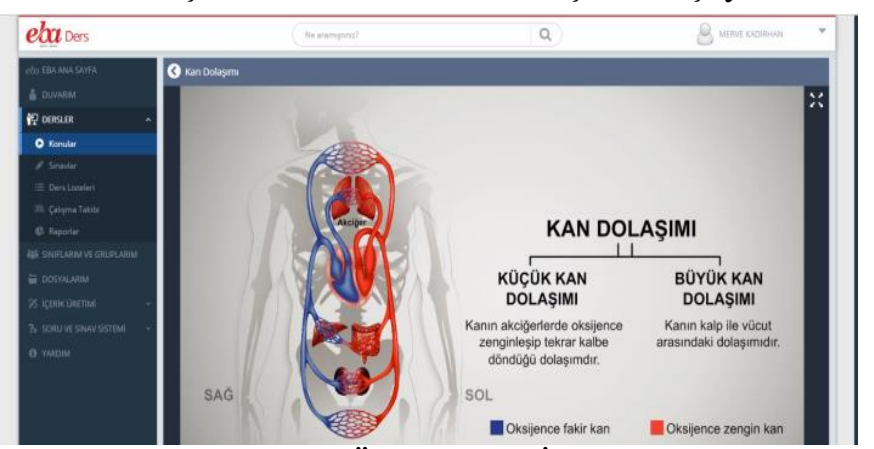

Şekil 1. Örnek EBA İçeriği

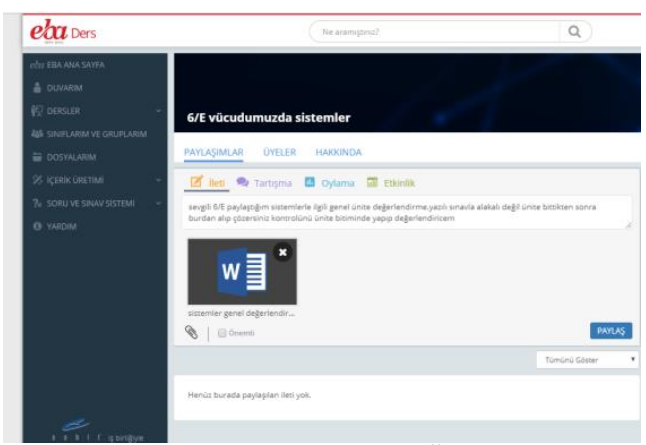

Şekil 2. Sanal Sinıf Örneği

Bu çerçevede EBA ortamında deney grubu için Şekil 2'deki gibi 6/E Vücudumuzda Sistemler isimli bir sınıf oluşturulmuş ve deney grubundaki öğrenciler bu sınıfa kaydedilmiştir. Harmanlanmış öğrenme ortamları, uzaktan eğitim ve yüz yüze eğitimin avantajlarını birleştirerek daha zengin bir öğrenme ortamı tasarlanmasına yardımcı olan bir öğretim yaklaşımıdır. Bu çerçevede dersten önce öğrencilere okul dışında EBA içerisindeki içerikleri izlemeleri ve etkinlikleri yapmaları için ödevler verilmiştir. Öğrencilerin içerikleri izleyip izlemedikleri EBA üzerinden takip edilmiştir. Böylece öğrencilerin derse gelmeden önce, dersle ilgili videoları izlemeleri ve etkinlikleri yapmaları sağlanmıştır. Ders içerisinde ise konu yine aynı içerikler kullanılarak özetlenmiş ve pekiştirmeye dönük etkinliklere yer verilmiştir. Böylece sınıf içerisinde öğrencilere daha çok etkinlik yapma firsatı sunulmuştur. Yapılan etkinlikler Tablo 2' de ayrıntılarıyla verilmiştir.

Tablo 2. Deney Grubunda Yapılan Etkinlikler

\begin{tabular}{|c|c|c|c|}
\hline KONU & SÜRE & SINIF İÇİ ETKINLIK & SINIF DIŞI ETKİNLIK \\
\hline $\begin{array}{l}\text { Dolaşım sistemi } \\
\text { yap1 ve organlar1 }\end{array}$ & 4 ders & $\begin{array}{l}\text { Küçük ve büyük dolaşımın çizimi, } \\
\text { gecçek kalp modeli incelemesi }\end{array}$ & $\begin{array}{l}\text { EBA konu anlatım videosu, online } \\
\text { test, etkileşimli uygulama (Şekil 3) }\end{array}$ \\
\hline $\begin{array}{l}\text { Kanın yapısı ve kan } \\
\text { alışverişi }\end{array}$ & 4 ders & $\begin{array}{l}\text { Kan hücrelerinin görevlerinin } \\
\text { anlatımı, kan bağışı ile ilgili video }\end{array}$ & $\begin{array}{l}\text { EBA konu anlatım videosu, online } \\
\text { test, etkileşimli uygulama }\end{array}$ \\
\hline $\begin{array}{l}\text { Solunum sistemi } \\
\text { yap1 ve organlar1 }\end{array}$ & 4 ders & $\begin{array}{l}\text { Solunum sistemi materyali } \\
\text { hazırlanmas1 (Șekil 4) }\end{array}$ & $\begin{array}{l}\text { EBA konu anlatım videosu, online } \\
\text { test, etkileşimli uygulama }\end{array}$ \\
\hline $\begin{array}{l}\text { Boşaltım sistemi } \\
\text { yapı ve organları }\end{array}$ & 4 ders & $\begin{array}{l}\text { Tişört üzerine boşaltım sistemi } \\
\text { yapılarının çizimi (Şekil 5) }\end{array}$ & $\begin{array}{l}\text { EBA konu anlatım videosu, online } \\
\text { test, etkileşimli uygulama }\end{array}$ \\
\hline
\end{tabular}

Deney grubunda sınıf dışı etkinlik olarak uygulanan etkileşimli uygulama çalışması z-kitaplarda bulunan online olarak açılabilen hareketli bir uygulamadır. Yapılan etkileşimli uygulama örneklerinden 
bir tanesi Şekil 3'te gösterilmiştir. Ayrıca sınıfta gerçekleştirilen etkinliklere ilişkin örnekler de Şekil 4 ve 5 'de sunulmuştur.

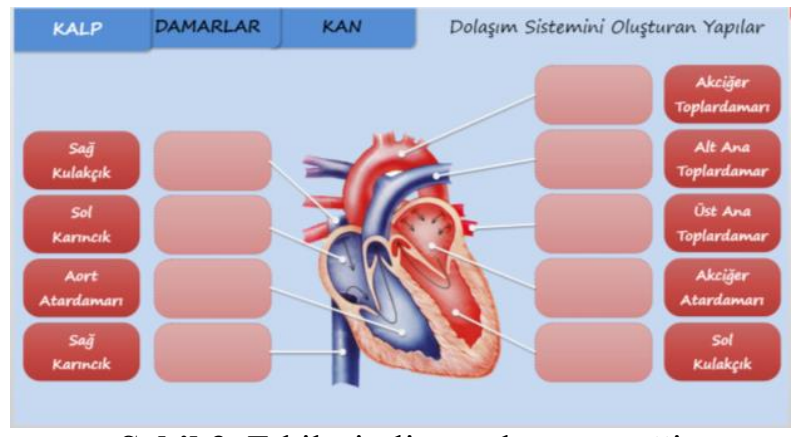

Şekil 3. Etkileşimli uygulama örneği

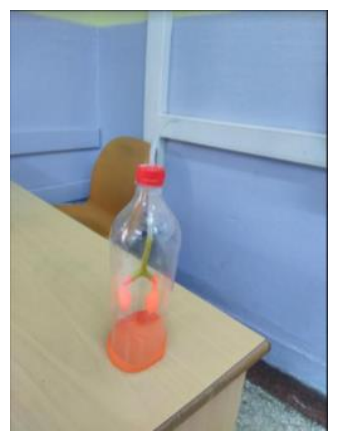

Şekil 4. Solunum Sistemi Modeli

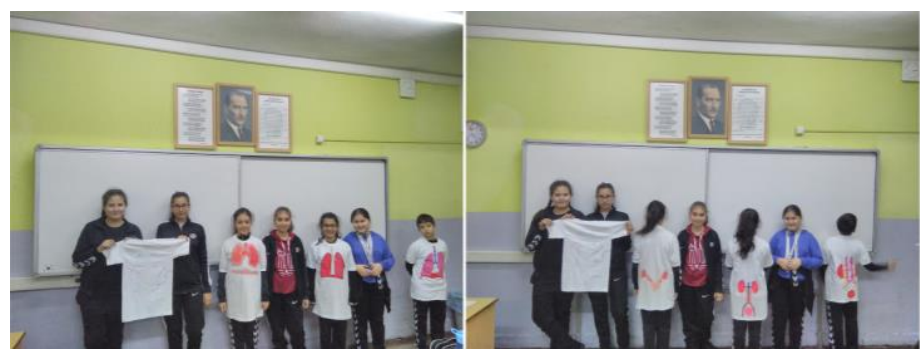

Şekil 5. Tişört etkinliği

Kontrol Grubu: Kontrol grubunda ise EBA üzerinden bir grup kurulmamış ders dış1 online iletişim sağlanmamıştır. Konular ders saati içerisinde yüz yüze sunulmuştur. Konular düz anlatım yöntemiyle sunulmuş, anlatılanların pekiştirilebilmesi için ise soru-cevap, kavram haritaları, konu sonu değerlendirme testleri uygulanmıştır. Ayrıca ders kitabında yer alan etkinlikler sınıf içinde gerçekleştirilmiştir.

\subsection{Verilerin Analizi}

Öğrencilerin akademik başarı testinden aldıkları puanlar 0 ile 100 arasında olabilmektedir. Tutum ölçeğinde hem toplam puanları hem de her bir faktöre ilişkin puanlar ise 20 ile 1000 arasında olacak şekilde standart puana dönüştürülmüştür. Veriler üzerinde parametrik istatistiklerin yapılıp yapılamayacağının belirlenmesi açısından deney ve kontrol gruplarına ilişkin toplanan veriler üzerin ayrı ayrı basıklık ve çarpıklık katsayıları incelenmiş, elde edilen katsayıların $-0,921$ ile 0,812 arasında değerler aldığ görülmüştür. $\mathrm{Bu}$ değerler $-1,5$ ile $+1,5$ aralı̆̆nda olduğundan verilerin normal dağıldığına karar verilmiştir. $\mathrm{Bu}$ doğrultuda toplanan veriler üzerinde aritmetik ortalama, standart sapma ve t testleri uygulanmış ve 0.05 anlamlılık düzeyi yeterli görülmüştür. Deneysel uygulamanın etkililiğine dönük analizlerde öntestteki küçük farklılaşmaları da kontrol altına almak amacıyla sontestöntest fark puanları kullanılmıştır.

\section{BULGULAR}

Deneysel çalışma öncesinde grupların fen bilgisine dönük akademik başarıları ve derse dönük tutumları açısından benzerliğine ilişkin bulgular Tablo 3'de özetlenmiştir.

Tablo 3. Deney ve Kontrol Gruplarının Deneysel Uygulama Öncesinde Fen Bilgisi Dersine Dönük Tutum ve Akademik Başarı Düzeylerinin Benzerliğine ilişkin Bulgular

\begin{tabular}{llllllll}
\hline & Grup & N & X & ss & t & sd & p \\
\hline \multirow{2}{*}{ Akademik Başarı } & Deney & 35 & 46.4 & 19.4 & \multirow{2}{*}{-2.090} & \multirow{2}{*}{73} & \multirow{2}{*}{0.040} \\
\cline { 2 - 5 } & Kontrol & 40 & 54.6 & 14.5 & & & \\
\hline $\begin{array}{l}\text { Günlük yaşam ve yeni bilgiler } \\
\text { öğrenme }\end{array}$ & Deney & 35 & 89.6 & 9.1 & \multirow{2}{*}{1.135} & \multirow{2}{*}{73} & \multirow{2}{*}{0.260} \\
\cline { 2 - 7 } & Kontrol & 40 & 86.7 & 12.5 & & & \\
\hline Uygulamada Güçlük & Deney & 35 & 75.6 & 18.9 & -1.648 & 73 & 0.104 \\
\hline
\end{tabular}




\begin{tabular}{|c|c|c|c|c|c|c|c|}
\hline & Kontrol & 40 & 82.8 & 18.8 & & & \\
\hline \multirow{2}{*}{ Problem Çözme } & Deney & 35 & 88.2 & 14.1 & \multirow{2}{*}{0.245} & \multirow{2}{*}{73} & \multirow{2}{*}{0.807} \\
\hline & Kontrol & 40 & 87.3 & 15.9 & & & \\
\hline \multirow{2}{*}{ Motivasyon } & Deney & 35 & 88.7 & 16.5 & \multirow{2}{*}{0.749} & \multirow{2}{*}{73} & \multirow{2}{*}{0.456} \\
\hline & Kontrol & 40 & 86.0 & 14.9 & & & \\
\hline \multirow{2}{*}{ Endişe } & Deney & 35 & 86.7 & 19.4 & \multirow{2}{*}{-0.247} & \multirow{2}{*}{73} & \multirow{2}{*}{0.806} \\
\hline & Kontrol & 40 & 87.7 & 15.7 & & & \\
\hline \multirow{2}{*}{ Tutum Toplam Puan } & Deney & 35 & 86.7 & 11.3 & \multirow{2}{*}{0.209} & \multirow{2}{*}{73} & \multirow{2}{*}{0.835} \\
\hline & Kontrol & 40 & 86.1 & 11.8 & & & \\
\hline
\end{tabular}

Tablo 3'e göre öğrencilerin fen bilgisi dersine dönük akademik başarıları arasında deneysel süreç öncesinde anlamlı bir farklılaşma olduğu görülmektedir $\left(\mathrm{t}_{(2-73)}=-2.090, \mathrm{p}<0.05\right)$. Ortalamalar incelendiğinde farklılaşmanın kontrol grubu lehine olduğu görülmektedir. Deneysel süreç öncesinde öğrencilerin fen bilgisi dersine dönük tutumları incelendiğinde, toplam puan açısından anlamlı bir farklılaşma olmadığ 1 görülmektedir $\left(\mathrm{t}_{(2-73)}=0.209, \mathrm{p}>0.05\right)$. Faktörler açısından da tutumların benzer olduğu görülmektedir. Tutum puan ortalamaları genel olarak değerlendirildiğinde ise gruplar arasında küçük farklılaşmalar olmakla birlikte hem deney hem de kontrol grubundaki öğrencilerin fen bilgisi dersine dönük tutumlarının oldukça yüksek olduğu görülmektedir. Hem akademik başarıdaki farklılaşmayı hem de faktörler arasındaki anlamlı olmamakla birlikte küçük farklılaşmaları kontrol altına almak amacıyla, deneysel uygulamanın etkililiğine ilişkin analizlerde sontest-öntest fark puanları kullanılmıştır. EBA içerikleriyle harmanlanmış fen bilimleri dersinin öğrencilerin Fen Bilgisi dersine dönük akademik başarıları ve derse dönük tutumları üzerindeki etkisine ilişkin bulgular Tablo 4'de özetlenmiştir.

Tablo 4. EBA İçerikleriyle Harmanlanmış Fen Bilimleri Dersinin Öğrencilerin Akademik Başarılarına ve Tutumlarına Etkisi

\begin{tabular}{|c|c|c|c|c|c|c|c|}
\hline & Grup & $\mathbf{N}$ & $\begin{array}{c}\mathbf{X} \\
\text { (Sontest- } \\
\text { Öntest } \\
\text { Fark) }\end{array}$ & SS & $\mathbf{t}$ & sd & $\mathbf{P}$ \\
\hline \multirow{2}{*}{ Akademik Başarı } & Deney & 35 & 22.4 & 17.3 & \multirow{2}{*}{2.059} & \multirow{2}{*}{73} & \multirow{2}{*}{$0.043 *$} \\
\hline & Kontrol & 40 & 14.1 & 17.5 & & & \\
\hline \multirow{2}{*}{$\begin{array}{l}\text { Günlük yaşam ve yeni bilgiler } \\
\text { öğrenme }\end{array}$} & Deney & 35 & 2.1 & 8.9 & \multirow{2}{*}{1.899} & \multirow{2}{*}{73} & \multirow{2}{*}{$0.05 *$} \\
\hline & Kontrol & 40 & -1.4 & 6.6 & & & \\
\hline \multirow{2}{*}{ Uygulamada Güçlük } & Deney & 35 & 7.1 & 14.4 & \multirow{2}{*}{0.447} & \multirow{2}{*}{73} & \multirow{2}{*}{0.565} \\
\hline & Kontrol & 40 & 5.5 & 15.5 & & & \\
\hline \multirow{2}{*}{ Problem Çözme } & Deney & 35 & 3.0 & 17.9 & \multirow{2}{*}{0.316} & \multirow{2}{*}{73} & \multirow{2}{*}{0.753} \\
\hline & Kontrol & 40 & 1.7 & 11.4 & & & \\
\hline \multirow{2}{*}{ Motivasyon } & Deney & 35 & 1.1 & 17.1 & \multirow{2}{*}{0.165} & \multirow{2}{*}{73} & \multirow{2}{*}{0.870} \\
\hline & Kontrol & 40 & 0.0 & 13.1 & & & \\
\hline \multirow{2}{*}{ Endişe } & Deney & 35 & 3.8 & 17.6 & \multirow{2}{*}{0.701} & \multirow{2}{*}{73} & \multirow{2}{*}{0.486} \\
\hline & Kontrol & 40 & 3.2 & 16.2 & & & \\
\hline \multirow{2}{*}{ Tutum Toplam Puan } & Deney & 35 & 2.8 & 10.4 & \multirow{2}{*}{0.411} & \multirow{2}{*}{73} & \multirow{2}{*}{0.486} \\
\hline & Kontrol & 40 & 1.4 & 6.18 & & & \\
\hline
\end{tabular}

Tablo 4'e göre öğrencilerin fen bilimleri dersine dönük akademik başarıları arasında deneysel süreç sonrasında anlamlı bir farklılaşma olduğu görülmektedir $\left(\mathrm{t}_{(2-73)}=2.059, \mathrm{p}<0.05\right)$. Ortalamalar incelendiğinde farklılaşmanın deney grubu lehine olduğu görülmektedir. Buna göre EBA içerikleriyle harmanlanmış Fen Bilimleri Dersinin öğrencilerin fen bilimleri dersine dönük akademik başarılarına, geleneksel yönteme göre anlamlı düzeyde daha fazla katkı sağladığı söylenebilir.

Tablo 4'de deneysel süreç sonrasında öğrencilerin fen bilgisi dersine dönük tutumları incelendiğinde, toplam puan açısından anlamlı bir farklılaşma olmadığı $\left(\mathrm{t}_{(2-73)}=0.411, \mathrm{p}>0.05\right)$, faktörler açısından incelendiğinde ise Günlük Yaşam ve Yeni Bilgiler Öğrenme faktöründe anlamlı bir farkl1laşma olduğu görülmektedir $\left(\mathrm{t}_{(2-73)}=1.899, \mathrm{p}<0.05\right)$. Ortalamalar incelendiğinde deney grubunun ortalamasını daha yüksek olduğu görülmektedir. Buna göre EBA içerikleriyle harmanlanmıș Fen Bilimleri Dersinin öğrencilerin Günlük Yaşam ve Yeni Bilgiler Öğrenme faktörüne ilişkin tutumlarına anlamlı düzeyde daha fazla katkı sağladığı söylenebilir. Öte yandan diğer faktörler açısından anlamlı 
olmamakla birlikte deney grubunun ortalamalarının kontrol grubundan daha yüksek olduğu söylenebilir.

\section{SONUÇ ve TARTIŞMA}

Deneysel uygulama öncesinde hem deney hem de kontrol grubundaki öğrencilerin fen bilimleri dersine dönük tutumları oldukça yüksektir. Fen bilimleri dersi, öğrencilerin günlük yaşamda karşılaştıkları birçok sorunun çözümünü içerdiği için ilgilerini çekmesi bu duruma neden olmuş olabilir. Yaşamın her anında dersten bir parça bulduklarından dolayı derse karşı olumlu tutum sergilemeleri beklendik bir durumdur. Tutum öntest sonuçları da bunu doğrulamaktadır. Araştırmada elde edilen bulgular literatürle de tutarlılık göstermektedir. Çakır, Şenler ve Taşkın, (2007) öğrencilerin fen bilimleri dersine dönük tutumlarının genel olarak yüksek olduğunu ifade etmektedir. Uyanık (2017) tarafından yapılan bir araştırmada 4. Sınıf öğrencilerin Fen Bilimleri dersine yönelik tutumlarının orta düzeyin biraz üzerinde olduğu belirlenmiştir. Çibir ve Özden (2017) tarafindan 4. Sınıf öğrencileri üzerinde yapılan bir araştırmada da benzer şekilde öğrencilerin fen bilimleri dersine yönelik olumlu tutuma sahip olduğu bulunmuştur. Abell ve Lederman (2007) ise bilimsel tutumun öğrencilerin fen başarılarını belirleyici önemli etkenlerden birisi olduğunu vurgulamaktadır. Oral ve McGivney (2011) tarafında yapılan bir araştırmada fen bilimleri alanlarında öğrencinin dersi sevmesi ve kendine güvenmesinin başarı ile doğru orantılı olduğunu belirtmiştir. Öte yandan öğrencilerin fen bilimlerine pozitif yönde tutum geliştirmesiyle birlikte fene olan ilgileri artırılması ve mesleki yönlendirme yapılabileceği vurgulanmaktadır (Mattern \& Schau, 2002). Yapılan araştırmalarda, öğrencilerin Fen Bilimleri dersi veya fen ile ilişkili diğer derslere yönelik olumlu tutumlara sahip olmalarıyla başarılı olmaları arasında anlamlı bir ilişki olduğu belirlenmiştir (Kozcu-Çakır, Şenler \& Göçmen-Taşkın 2007; Türkmen, 2002). Çibir ve Özden (2017) ise öğrencilerin fene ilişkin olumlu tutumlara sahip olmasının, istendik eğitim çıktılarından olduğunu vurgulamaktadır.

EBA içerikleriyle harmanlanmış Fen Bilimleri Dersinin öğrencilerin fen bilgisi dersine dönük akademik başarılarına, geleneksel yönteme göre anlamlı düzeyde daha fazla katkı sağlamaktadır. $\mathrm{Bu}$ bulgu literatürle de tutarlılık göstermektedir. Akgündüz ve Akinoglu (2013) tarafindan 7. Sinıf fen bilgisi dersinde dönük gerçekleştirilen bir araştırmada, öğrencilerin "Vücudumuzda Sistemler" ünitesine dönük akademik başarılarına harmanlanmış öğrenmenin Sosyal medya destekli öğrenmenin ve geleneksel öğretime göre anlamlı düzeyde daha fazla katkı sağladığı sonucuna ulaşılmıştır. Pereira ve arkadaşları (2007) tarafında insan anatomisin konusuna dönük yapılan harmanlanmış, öğrenmeye ilişkin çalışmada da harmanlanmış öğrenmenin akademik başarıyı artırdığını belirlenmiştir. Balaman ve Tüysüz (2011) tarafından harmanlanmış öğrenmenin 7. Sınıf öğrencilerinin fen bilimleri dersindeki başarı, tutum ve motivasyonlarına etkisini belirlemek amacıyla yapılan çalışmada da benzer şekilde harmanlanmış öğrenmenin yüz yüze öğrenmeye göre akademik başarıya anlamlı düzeyde daha fazla katk1 sağladığı belirlenmiştir. Çetinkaya (2017) tarafından fen eğitiminde modelleme temelli kişiselleştirilmiş harmanlanmış öğrenmenin başarıya etkisini belirlemek amacıyla yapılan araştırmada da bezer şekilde sonuçlara erişildiği raporlanmıştır. Literatür incelendiğinde bundan önce yapılan çalışmalarda da hangi ders üzerinde harmanlanmış bir öğrenme yöntemi uygulanırsa uygulansın hepsinde akademik başarı düzeyi, geleneksel yönteme göre anlamlı düzeyde daha yüksek çıkmıştır. Örneğin; Çiftçi ve Dönmez (2015), T.C. İnkılap Tarihi ve Atatürkçülük dersinde harmanlanmış öğrenme yönteminin akademik başarı ve tutuma etkisini araştırarak deney ve kontrol gruplu deneysel desen kullanmışlardır. Deney grubunda harmanlanmış öğrenme, kontrol 1'e çevrimiçi, kontrol 2'ye yüz yüze öğrenme yöntemi uygulamışlardır. Gruplara deneysel süreç öncesi öntest ve deneysel süreç sonrası sontest uygulanarak sonuçlar karşılaştırıldığında harmanlanmış öğrenme ortamının uygulandığı deney grubunun sonuçlarının anlamlı bir şekilde farklılaşarak yükseldiği görülmüştür. Uluyol ve Karadeniz ve (2009) tarafından yapılan araştırmada da harmanlanmış öğrenmenin öğrenci başarısı üzerinde anlamlı bir farklılık oluşturduğunu göstermektedir. Yapılan araştırmaya yaş grubu ve uygulanan ders açısından benzer olan Özerbaş ve Benli (2015)' nin yapmış olduğu araştırma da sonuçların anlamlı olarak deney grubunda farklılaştığını kanıtlamaktadır. Bağc1 ve Yalın (2018) da 5E modeline uygun olarak denetim odağına uyarlanan harmanlanmış öğrenme kullanılan bir deney grubunun kontrol grubuna göre daha yüksek akademik başarı gösterdiğini vurgulamaktadır. Çırak Kurt, Yıldırım ve Cücük (2018) tarafindan 2000-2016 yılları arasında tamamlanmış 225 çalışma içerisinden belirlenen 36 deneysel çalışmanın sonuçlarının meta-analiz yöntemiyle incelendiği bir araştırmada harmanlanmış, 
öğrenmenin öğrenen başarısı üzerinde güçlü düzeyde ve \%70.8'lik bir katma değere sahip olduğunu rapor edilmiştir. Diğer yandan yapılan analizler neticesinde harmanlanmış, öğrenmenin yüz yüze öğrenme ve çevrimiçi öğrenmeye kıyasla öğrenci başarısında daha olumlu sonuçlar ortaya koyduğu belirlenmiştir.

EBA içerikleriyle harmanlanmış Fen Bilimleri Dersinin öğrencilerin Günlük Yaşam ve Yeni Bilgiler Öğrenme faktörüne ilişkin tutumlarına anlamlı düzeyde daha fazla katkı sağlamaktadır. Öte yandan diğer faktörler açısından anlamlı olmamakla birlikte deney grubunun ortalamaları, kontrol grubundan daha yüksektir. Literatür incelendiğinde harmanlanmış öğrenme ile Fen Bilgisi Dersine karşı öğrencilerin tutumlarına olumlu katkılarının olduğuna ilişkin pek çok kanıta rastlamak mümkündür (Akkuş \& Keskin, 2016; Çakır, Şenler \& Taşkın, 2007; Çiftçi \& Dönmez, 2015; El-Deghaidy \& Nouby, 2008; Güler \& Şahin, 2015; Oh \& Park, 2009). Öte yandan harmanlanmış öğrenmenin sadece belirli düzeydeki öğrenciler üzerinde değil yaş değişkeni farklılaştığında da tutum üzerinde yapılan araştırmalar gereği anlamlı farklılaşmalar olduğu incelenmiştir (Güler \& Şahin, 2015). Demirer (2009) yapmış olduğu araştırmasında harmanlanmış öğrenme yaklaşımının tutuma etkini inceleyerek deney grubu lehine olumlu sonuçlara ulaşıldığını ifade etmektedir. Ayrıca Demirer deney sürecinin sonunda öğrencilerin görüşlerini almış ve bu uygulamaya dönük öğrenci görüşlerinin oldukça olumlu olduğunu ifade etmiştir.

Sonuç olarak harmanlanmış öğrenme ortamının Fen Bilimleri dersinde kullanılması durumunda öğrencilerin akademik başarılarına ve tutumlarına olumlu yönde katkı sağlayabileceği söylenebilir. Araştırma kapsamında EBA içerikleriyle Fen Bilimleri dersi harmanlandığında laboratuvar kullanılması gereken zahmetli ve tehlikeli konularda sanal etkileşimli deneylerle, benzeşim yoluyla gerçeğe yakın hazırlanmış video içerikleriyle, çağımızın gereği olan teknolojinin kullanımı sonucu hazırlanan çevrimiçi alıştırma uygulamalarıyla öğrenciler sınıf dışında da akademik gelişimlerine katkı sağlayabilir. Sınıfta yüz yüze etkileşim daha da artmakta ve farklı etkinlikler yapma firsatı doğduğundan dolayı kazanımların kazanılması öğrenciler açısından kolaylaşmaktadır. Bu sebeple dersteki akademik başarıya katkı sağladığı ve dersi eğlenceli hale geldiği için derse yönelik tutum artış gösterebilmektedir. $\mathrm{Bu}$ çerçevede öğretmelerin derslerinde harmanlanmış öğrenme yaklaşımını kullanmaları önerilebilir.

\section{KAYNAKÇA}

Abell, S.K. \& Lederman, N.G. (2007). Handbook of research on science education. Lawrence Erlbaum Asssociates: N. Jercy.

Akgunduz, D. \& Akinoglu, O. (2016). The effect of blended learning and social media-supported learning on the students' attitude and self-directed learning skills in science education. The Turkish Online Journal of Educational Technology, 15(2), 106-115

Akkuş, M. ve Keskin, Y. (2016). Harmanlanmış öğrenme ile ilgili öğrenci tutumlarının incelenmesi. Eğitim ve Ögretim Araştırmaları Dergisi, 5, 2, 33, 2146-9199

Bağc1, H. ve Yalın, H.I. (2018). Harmanlanmış ögrenme ortamında denetim odağına göre uyarlanmış 5e modelinin öğrencilerin akademik başarısına etkisi, Kuramsal Eğitim Bilim Dergisi, 11(3), 562-585

Balaman, F. ve Tüysüz, C. (2011) Harmanlanmıș öğrenme modelinin 7. Sınıf öğrencilerinin fen ve teknoloji dersindeki başarılarına, tutumlarına ve motivasyonlarına etkisinin incelenmesi. Batı Anadolu Ĕgitim bilimleri Dergisi, 2(4), 75-90

Balaman, F. ve Tüysüz, C. (2011). Harmanlanmış öğrenme modelinin 7. sınıf öğrencilerinin fen ve teknoloji dersindeki başarılarına, tutumlarına ve motivasyonlarına etkisinin incelenmesi. Batı Anadolu Eğitim Bilimleri Dergisi, 2(4), 75-90.

Büyüköztürk, Ş. (2002). Sosyal bilimler için veri analizi el kitabı. Ankara: Pegema Yayıncılık.

Çakır, N. Şenler, B. ve Taşkın, B. (2007). İlköğretim ikinci kademe öğrencilerinin fen bilgisi dersine yönelik tutumlarının incelenmesi. Türk Ĕgitim Bilimleri Dergisi, 5(4), 637-655

Çetinkaya, M (2017). Fen eğitiminde modelleme temelinde düzenlenen kişiselleştirilmiş harmanlanmış öğrenme ortamlarının başarıya etkisi. Ordu Üniversitesi Sosyal Bilimler Araştırmaları Dergisi, 7(2), 287-296

Çırak Kurt, S., Yıldırım, İ. \& Cücük, E. (2018). The effects of blended learning on student achievement: A metaanalysis study. Hacettepe University Journal of Education, 33(3), 776-802.

Çırak, S. (2017). Bir Harmanlanmış Öğrenme Deneyimi. İlköğretim online, 16(2), 860-886. 
Çibir, A. ve Özden, M. (2017). İlkokul öğrencilerinin fen dersine yönelik tutumları: Kütahya örneği. Ĕgitim Bilimleri Araştırmaları Dergisi, 7(2), 45-61.

Çiftçi, B. ve Dönmez, C. (2015). T.C. inkılap tarihi ve atatürkçülük dersinde harmanlanmış öğrenme yönteminin öğrencilerin akademik başarısı ve tutumuna etkisi. Turkish Study, 10(15), 235-254.

Dağ, F. (2011). Harmanlanmış (karma) öğrenme ortamları ve tasarımına ilişkin öneriler. Ahi Evran Üniversitesi Ĕ̈itim Fakültesi Dergisi, 12(2), 73-97.

EBA, (2019). EBA Hakkinda. http://www.eba.gov.tr/hakkimizda

El-Deghaidy H. \& Nouby, A. (2008). Effectiveness of a blended e-learning cooperative approach in an Egyptian teacher education programme. Computers \& Education, 51, 988-1006.

Graham, C.R. (2006). Blended Learning Systems. Definition, Current Trends, and Future Directions. The Handbook of Blended Learning. ed. C. J. Bonk, \& C. R. Graham. San Fransisco: Pfeiffer: 3-21.

Güler, B. ve Şahin, M. (2015). Karma öğrenme yönteminin ilköğretim fen bilgisi öğretmen adaylarının teknolojiye yönelik tutumlarına, öz-düzenleme ve bilimsel süreç becerilerine etkisi. Necatibey Eğitim Fakültesi Elektronik Fen ve Matematik Ĕ̈itimi Dergisi, 9(1), 108-127.

Horton, W. (2000). Designing web based training. NY, Chichester, Weinheim, Brisbane, Singapore, Toronto: John Wiley.

Kılıç, S. (2013). Örnekleme yöntemleri. Journal of Mood Disorders, 3(1):44-66.

Kozcu-Çakır, N., Şenler, B. ve Göçmen-Taşkın, B. (2007). İlköğretim II. kademe öğrencilerinin fen bilgisi dersine yönelik tutumlarının belirlenmesi. Türk Eğitim Bilimleri Dergisi, 5(4), 637-655.

Mattern, N. \& Schau, C. (2001). Gender difference in attitude-achievement relationships over time among white middle school students. Journal of Research in Science Teaching, 39, 324-340.

Morgan, K.R. (2002). Blended learning: A strategic action plan for a new campus. Seminole, FL: University of Central Florida.

Oh, E. \& Park, S. (2009). How are universities involved in blended instruction? Educational Technology \& Society, 12 (3), 327-342.

Oral, I. ve McGivney, E. (2011). Türkiye'de Matematik ve Fen Bilimleri Alanlarında Öğrenci Performansı ve Başarının Belirleyicileri: TIMSS 2011 Analizi. http://www.egitimreformugirisimi.org/timss-2011-analizi/ adresinden 05/01/2095 tarihinde erişilmiş̧tir.

Özerbaş, M.A. ve Benli, N. (2015). Harmanlanmış öğrenme ortamının öğrenci akademik başarısına ve tutumuna etkisi. Gazi Ĕ̈itim Fakültesi Dergisi, 35(1), 87-108.

Pereira, J. A., Pleguezuelos, E., Merí, A., Ros, A. M., Carmen, M., Toma's, M. \& et al. (2007). Effectiveness of using blended learning strategies for teaching and learning human anatomy. Medical Education, 41(2), 189- 195.

Sarıtepeci, M. ve Çakır, H. (2015). Harmanlanmış öğrenme ortamlarının ortaokul öğrencilerinin derse katılımı ve akademik başarısına etkisi: Sosyal Bilgiler Dersi Örneği, Türk Eğitim Derneği, 40(177), 203-216.

Singh, H., Reed, C. (2001). A white paper: Achieving success with blended learning. Erişim adresi: https://maken.wikiwijs.nl/userfiles/f7d0e4f0bd466199841ede3eea221261.pdf

Smelser, L.M. (2002). Making Connections in Our Classrooms: Online and Off. Paper presented at the Annual Meeting of the Conference on College Composition and Communication, Chicago, IL.

Şener, N. ve Taş, E. (2016). Öğrencilerin fen bilimlerine yönelik tutumlarını belirlemeye yönelik bir ölçek geliştirme çalı̧̧ması, Ordu Üniversitesi, Sosyal Bilimler Araştırmaları Dergisi, 278-300.

Teker, S. Kurt, M. ve Karamustafaoğlu, O. (2017). Işığın ve sesin yayılması' ünitesini buluş yoluyla öğrenmenin öğrenci başarısı ve tutumuna etkisi. Adlyaman Üniversitesi Sosyal Bilimler Enstitüsü Dergisi, 10(27), 836863.

Thorne, K. (2007). Blended learning: How to integrate online and traditional learning. Glasgow: Kogan Page.

Türkmen, L. (2002). Sınıf öğretmenliği 1.sınıf öğrencilerinin fen bilimleri ve fen bilgisi öğretimine yönelik tutumları. Hacettepe Üniversitesi Ĕ̈itim Fakültesi Dergisi, 23, 218-228.

Uluyol, Ç. ve Karadeniz, Ş. (2009) Bir harmanlanmış öğrenme ortamı örneği: öğrenci başarısı ve görüşleri. Yüzüncü Yll Üniversitesi Ĕgitim Fakültesi Dergisi, 6(1), 60-84.

Usta, E. ve Mahiroğlu, A. (2008). Harmanlanmış öğrenme ve çevirim içi öğrenme ortamlarının akademik başarı ve doyuma etkisi. Ahi Evran Üniversitesi Kirşehir Eğitim Fakültesi Dergisi, 9(2), 1-15.

Uyanık, G. (2017). İlkokul öğrencilerin fen bilimleri dersine yönelik tutumları ile akademik başarıları arasındaki ilişki. $T \ddot{U} B A V, 10(1), 86-93$. 
Ünsal, H. (2012). Harmanlanmış öğrenmenin başarı ve motivasyona etkisi, Türk Eğitim Bilimleri Dergisi, 10(1), 1-27.

Wilson, D., Smilanich, E. (2005). The other blended learning. San Francisco: Pfeiffer.

Yolcu, H. (2015). Harmanlanmış (Karma) öğrenme ve uygulama esasları, The Journal of Academic Social Science Studies, 33, 255-260. 